\title{
LOCATION OF PREHOSPITAL CARE BASIS THROUGH COMBINED FUZZY AHP AND GIS METHOD
}

\author{
Marco Tiznado \\ Departamento de Ingeniería Industrial, Facultad de Ingeniería \\ Universidad de Concepción, Chile \\ E-mail: marcotiznado@udec.cl \\ Lorena Pradenas \\ Departamento de Ingeniería Industrial, Facultad de Ingeniería \\ Universidad de Concepción, Chile \\ E-mail: 1pradena@udec.cl
}

\begin{abstract}
EMS (Emergency Medical Services) provides emergency medical care and prehospital service. Response times are critical and represent the basis of good care for injured or sick individuals. The present study aims to determine the optimal location of new EMS bases. The location of these facilities has been addressed in the literature according to multiple perspectives, including qualitative considerations. A method that incorporates both the qualitative and quantitative methods by means of Geographic Information System (GIS) and a Fuzzy Analytic Hierarchy Process (FAHP) models is proposed. The current approach is flexible and tolerant to uncertainty, and it also considers the experience of the staff. A case study is performed in a city, obtaining a new location to meet the health care deficit.
\end{abstract}

Keywords: EMS locations, Fuzzy AHP, location of facilities, GIS.

\section{Introduction}

In a prehospital health care service of the EMS type, response time is critical and represents the basis of good care for injured people and those in health emergencies. The locations of public facilities, especially emergency, fire and police stations have a strategic dimension. In general, these types of problems can be evaluated using multicriteria models to improve both service level and coverage. The current study resolves the locations of facilities for EMS bases in a medium size city in Chile under a flexible approach.

\section{Problem description}

The overall problem can be understood as a p-median problem with qualitative features not defined by means of a mathematical model. Thus, a flat space represented by $x-y$ coordinates with a dispersed set $\mathrm{L}=\left\{1_{1}, 1_{2} \ldots 1_{\mathrm{n}}\right\}$ of health care centers can be defined, 
where $\mathrm{M}=\left\{\mathrm{m}_{1}, \mathrm{~m}_{2} \ldots \mathrm{m}_{\mathrm{n}}\right\}$ corresponds to the set of current bases. The set M must satisfy the demand of the spatially distributed users, defined as $U=\left\{u_{1}, u_{2} \ldots u_{n}\right\}$. Given the fact that there are a number of alternatives, L, to locate bases, an optimal solution to address to the posed restrictions is required. The problem is thus summarized by a Cartesian $x-y$ plane containing a set of EMS bases (M) identified by (*); a set of candidate locations (L), identified by $(+)$; and a set of users that require health care, identified by (.). The cost corresponds to minimizing the $d_{u l}$ distance (associated to a time).

\section{Literature Review}

Facility location models are generally addressed by multiple criteria, such as multiattribute (MADM) and multi-objective (MODM) models.

In the study by (Roig-Tierno et al., 2013), a Geographic Information System (GIS) was used. This system can provide a full representation of the spatial and physical realities of both humans and economic variables. In addition, the Analytic Hierarchy Process (AHP) was used to obtain the best location for the establishment of a shopping center within a city. The work was divided into two stages: the first stage consisted of statistical analysis, which considered the offers presented by a number of scattered available stores. The analysis also considered the demand presented by the surrounding population. In the second stage, evaluations were performed by AHP to assess the options extracted from the previous stage. The proposed method is practical for determining the location of future facilities, and good results are obtained.

The study by (Vahidnia et al., 2009) addressed the decision factors for the location of a new hospital and the uncertainty in the problem. The authors used GIS combined with the Fuzzy Analytic Hierarchy Process (FAHP). The latter presented an improvement with respect to the traditional process, imitating the way humans make decisions and considering information while incorporating a degree of uncertainty. Three different methods were applied based on the fuzzy theory to generate the FAHP with the goal of determining whether any of these processes made comparatively better decisions than the other or if there was a significant difference between them. Such a result was not observed because all of the processes converged to the same solution. Finally, the authors established the development of a high performance application for the location of a hospital as a challenge

\section{Method}

The proposed method illustrated in Figure 1 is based on a previous method (Vahidnia, et al., 2009) (Chang et al., 2008). Stage 1 allows the collection of data drawn from different sources, integrating them in the GIS platform and obtaining conclusions about the criteria of importance for AHP. The GIS analysis, where kernel density estimation and Getis-Ord $\mathrm{Gi}^{*}$ statistical tools are used, is of special interest.

In Stage 1, the decision maker generates an idea according to the geo demand and geo competition of the zone. In other words, the decision maker identifies deprived zones Subsequently, the decision maker continues with the analysis of the alternatives or appropriate candidates (Stage 2), performed by software equipped with a MADM called the Analytic Hierarchy process (AHP, Saaty 2008), with an extension to the fuzzy theory 
(FAHP) from this last stage. Fuzzy AHP (FAHP) has the same features as the AHP but with improvements to the inaccuracy or subjectivity of the human judgment as a result of using the fuzzy logic theory

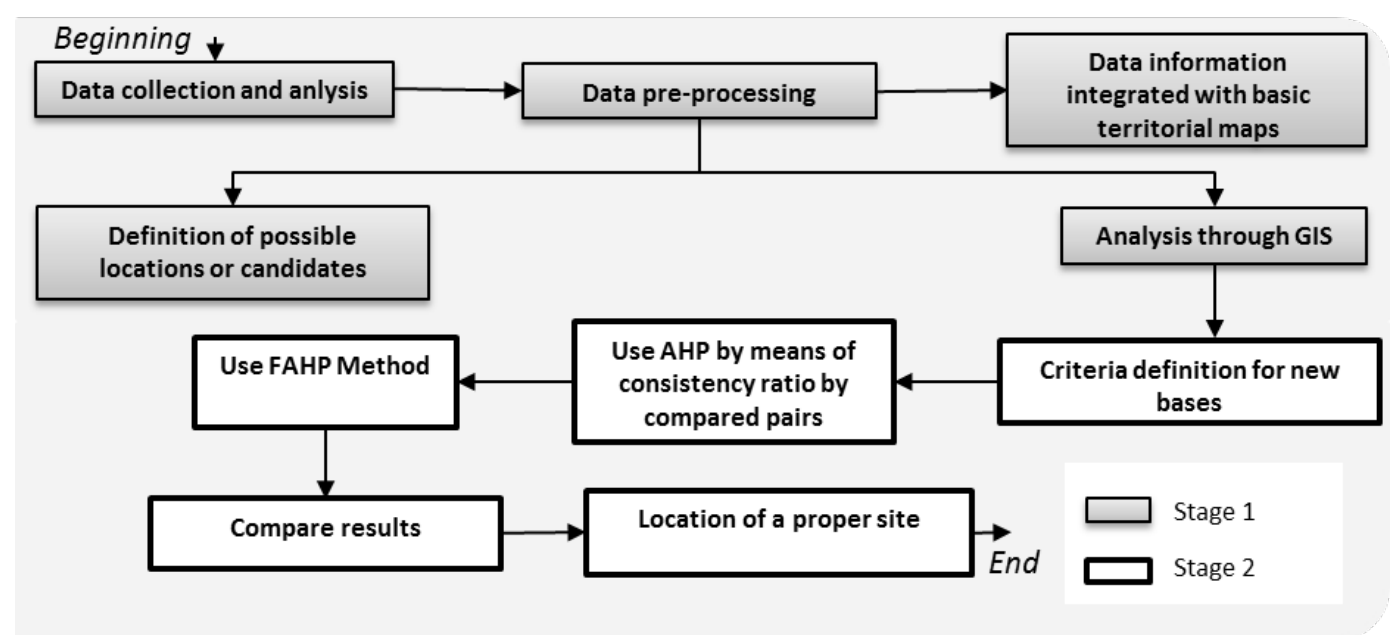

Figure 1 Proposed method.

Judgments made by the decision makers with respect to alternatives and other criteria can be converted into fuzzy numbers to calculate the importance of the weights using AHP. These values are used to construct the pairwise comparison matrix of the AHP.

Several FAHP models have been proposed, all of which are based on the utilization of triangular numbers (Vahidnia, et al., 2009).

\section{Study case (results)}

A study case was carried out in the chosen city, (located $500 \mathrm{~km}$ from Santiago, Chile). In Figure 2, the layer shown in a blue color range corresponds to the population density, according to the kernel density estimator analysis (Roig-Tierno et al., 2013). There is a direct correlation between population concentration and color density.

The colored dots correspond to the level of significance for the time delay of care after emergency calls. These dots may correspond to an identifiable pattern. The red colored dots indicate a significantly higher delay level (more than 15 minutes). This is the time limit within which EMS can be considered to provide acceptable care within an urban zone, as there is a direct relation between the survival probability of a patient and the delay in care.

In contrast, the green dots indicate that this demand was properly met. The remaining dots are calls from which a pattern was not determined i.e., the null randomness hypothesis was not rejectable according to the Getis-Ord Gi* method (Mitchell, 2005). 


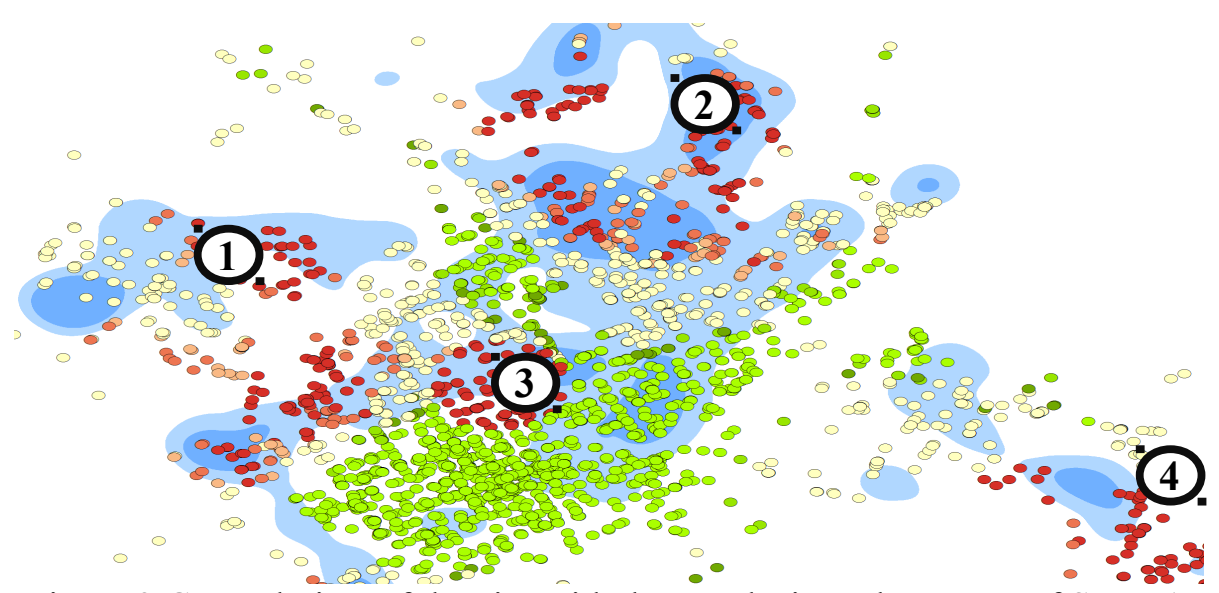

Figure 2 General view of the city with data analysis to the output of Stage 1.

Working with the coordinator physician from the institution, the following criteria and sub-criteria were established. The list provides three columns (Table 1), in which the levels according to the structure of the FAHP model are presented. The alternatives proposed correspond to the resulting zones from stage 1 .

Table 1

Representation of the Saaty fuzzy scale

\begin{tabular}{|c|c|c|}
\hline Criteria & Sub-criteria & Alternatives \\
\hline Demographics & $\begin{array}{l}\text { Population growth } \\
\text { Flood charts } \\
\text { Population density }\end{array}$ & Zone 1 \\
\hline $\begin{array}{l}\text { Distance from routes } \\
\text { Versatility } \\
\text { Accident rate } \\
\text { Prevalence rate } \\
\text { Availability }\end{array}$ & & $\begin{array}{l}\text { Zone } 2 \\
\text { Zone } 3\end{array}$ \\
\hline
\end{tabular}

The points considered for each of the criteria mentioned in the method are detailed as follows: Demographics, this is the only category or criterion with sub-criteria because it evaluates the target population. Density refers to the number of inhabitants per surface area. However, flood charts provide no possibility of anticipating problems as a result of disasters such as tsunamis; Distance from routes, proximity of the EMS base, important avenues that imply better accessibility and travel time; Versatility, in this sense; EMS intends to maximize the existing infrastructure. Therefore, more complex facilities may be preferred; Accident rate, accidents respond to human behavior patterns and, to a lesser extent, to the poor implementation of traffic solutions; Prevalence rate, people, either by average age or other environmental and/or socioeconomic factors, are predisposed to some diseases over others; Availability, this parameter is associated with the possibility of opting for an emergency vehicle. 
A Graphic User Interface (GUI) computer program was developed in Matlab R2013a and validated.

Table 2 shows the criteria assessed by the EMS. The most important of these criteria is the availability of an emergency vehicle. In addition, the evaluations correspond to the fuzzy numbers. The results generated by the method indicate that zone 1 has a weight of 0.235 , zone 2 has a weight of 0.213 and zone 3 has a weight of 0.554 . Location (3) is characterized by low population density and no apparent response time pattern in the superposition of those two layers. This location is surrounded by "not significant" data (yellow dots) and "good service" data. Thus, rather than a coverage problem or deficiency of the EMS, the problem at Location (3) may be caused by traffic infrastructure or congestion.

Table 2

Attribute comparison for the AHP: Fuzzy model

\begin{tabular}{|c|c|c|c|c|c|c|c|}
\hline & $\mathrm{I}$ & II & III & IV & $\mathrm{V}$ & VI & $\mathbf{W}$ \\
\hline I. Demographics & $1,1,1$ & $0.3,0.5,1$ & $0.3,0.5,1$ & $0.3,0.5,1$ & $1,1,1$ & $0.3,0.5,1$ & 0.08 \\
\hline II. Distance from routes & $1,1,1$ & $1,1,1$ & $1,1,1$ & $0.3,0.5,1$ & $1,1,1$ & $0.3,0.5,1$ & 0.14 \\
\hline III. Versality & $1,2,3$ & $1,1,1$ & $1,1,1$ & $0.3,0.5,1$ & $1,2,3$ & $0.3,0.5,1$ & 0.17 \\
\hline IV. Accident rate & $1,2,3$ & $1,2,3$ & $1,2,3$ & $1,1,1$ & $0.25,0.33,0.5$ & $0.3,0.5,1$ & 0.19 \\
\hline V.T. Prevalence & $1,2,3$ & $1,2,3$ & $0.3,0.5,1$ & $2,3,4$ & $1,1,1$ & $0.25,0.33,0.5$ & 0.15 \\
\hline Availability & $1,2,3$ & $1,2,3$ & $1,2,3$ & $1,2,3$ & $2,3,4$ & $1,1,1$ & 0.26 \\
\hline
\end{tabular}

\section{Conclusions}

According to the assessments carried out with the support of the coordinating physician, the first option to be considered is in zone 1.

This approach is useful because it allows the integration and analysis of the existing information by means of GIS, while FAHP allows the determination of a solution through judgments by the operator.

\section{REFERENCES}

Roig-Tierno, N., Baviera-Puig, A., Buitrago-Vera, J., \& Mas-Verdu, F. (2013). The retail site location decision process using GIS and the analytical hierarchy process. Applied Geography, 40, 191-198.

Vahidnia, M. H., Alesheikh, A. a, \& Alimohammadi, A. (2009). Hospital site selection using Fuzzy AHP and its derivatives. Journal of environmental management, 90(10), 3048-56.

Chang, N.-B., Parvathinathan, G., \& Breeden, J. B. (2008). Combining GIS with Fuzzy multicriteria decision-making for landfill siting in a fast-growing urban region. Journal of environmental management, 87(1), 139-153.

Saaty, T. L. (2008). Decision making with the analytic hierarchy process. International Journal of Services Sciences, 1(1), 83-98.

Mitchell, A. (2005). The ESRI Guide to GIS Analysis, Volume 2: Spatial Measurements \& Statistics, ESRI Press, 158948116X, Redlands, California 